\title{
CyberKnife radiosurgery for an intracardiac metastasis
}

\author{
A G R Martin, ${ }^{1}$ D J Coltart, ${ }^{2,3}$ P N Plowman ${ }^{1,4}$ \\ ${ }^{1}$ The CyberKnife Centre, London, UK; \\ ${ }^{2}$ Guy's and St. Thomas' NHS Foundation Trust, London, UK; \\ ${ }^{3}$ The Harley Street Clinic, London, UK; \\ ${ }^{4}$ Barts and The London NHS Trust, London, UK \\ Correspondence to A G R Martin, agrmartin@hotmail.co.uk
}

\section{DESCRIPTION}

Intracardiac tumours move both with breathing and with the cardiac cycle; they therefore pose unique problems for radiotherapy delivery. Conventional radiotherapy must encompass the tumour with a margin to account for this motion, and the prescription is limited by myocardial radiation tolerance. The greater accuracy of radiosurgery allows higher radiation-dose deposition, with relative myocardial sparing.

A 67-year-old male underwent surgical resection of a right-ventricular metastatic adenocarcinoma in March 2009 , followed by postoperative conventional radiotherapy close to myocardial tolerance (40 Gy in 20 fractions). Six months later the tumour regrew, obstructing the ventricle and leading to heart failure, with a prognosis of days.
Further surgery was not possible. He was treated with fractionated radiosurgery (25 Gy in five fractions) using the CyberKnife system (Accuray, Sunnyvale, California, USA) (figure 1).

Implanted pericardial fiducial markers allowed near realtime x-ray monitoring of the tumour and heart position with breathing. The integrated Synchrony system correlated fiducial position with real-time monitoring of chestwall movement, enabling the radiation beam to track the moving tumour continuously. Cardiac cycle motion was accounted for by outlining the tumour position on three different phases of a cardiac-gated CT scan, fused with the radiotherapy planning CT (figure 2 ).

Echocardiography showed a $27 \%$ reduction in crosssectional tumour area at 1 week following treatment, and

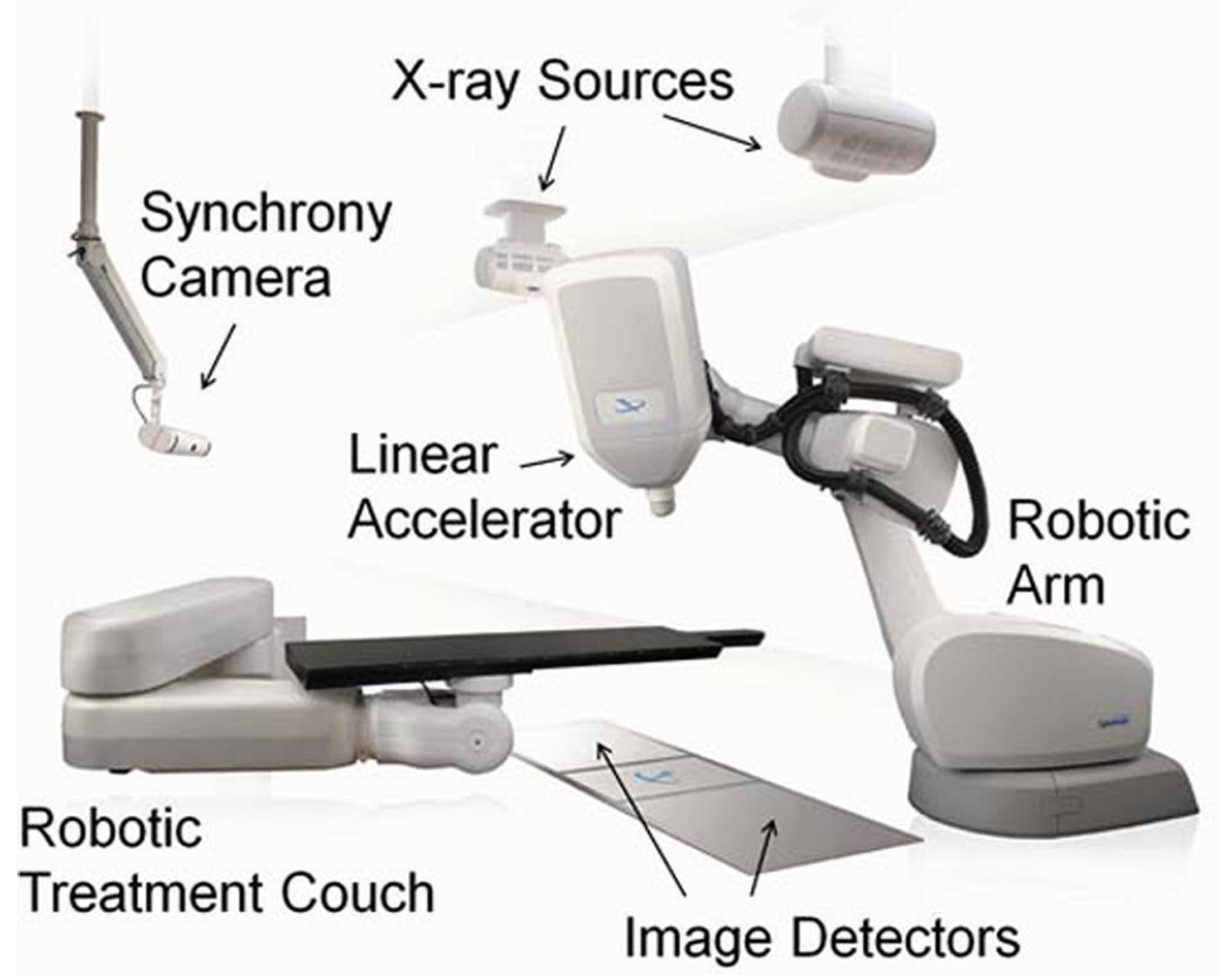

Figure 1 Picture of the CyberKnife system components. A compact linear accelerator is mounted on a six-joint robotic arm, which can move freely around the patient. Two kilovoltage x-ray sources are positioned orthogonally for near 'real-time' target imaging. The infrared Synchrony camera can monitor chest-wall movement via light-emitting diodes placed on the patient's chest. 


\section{BMJ Case Reports}

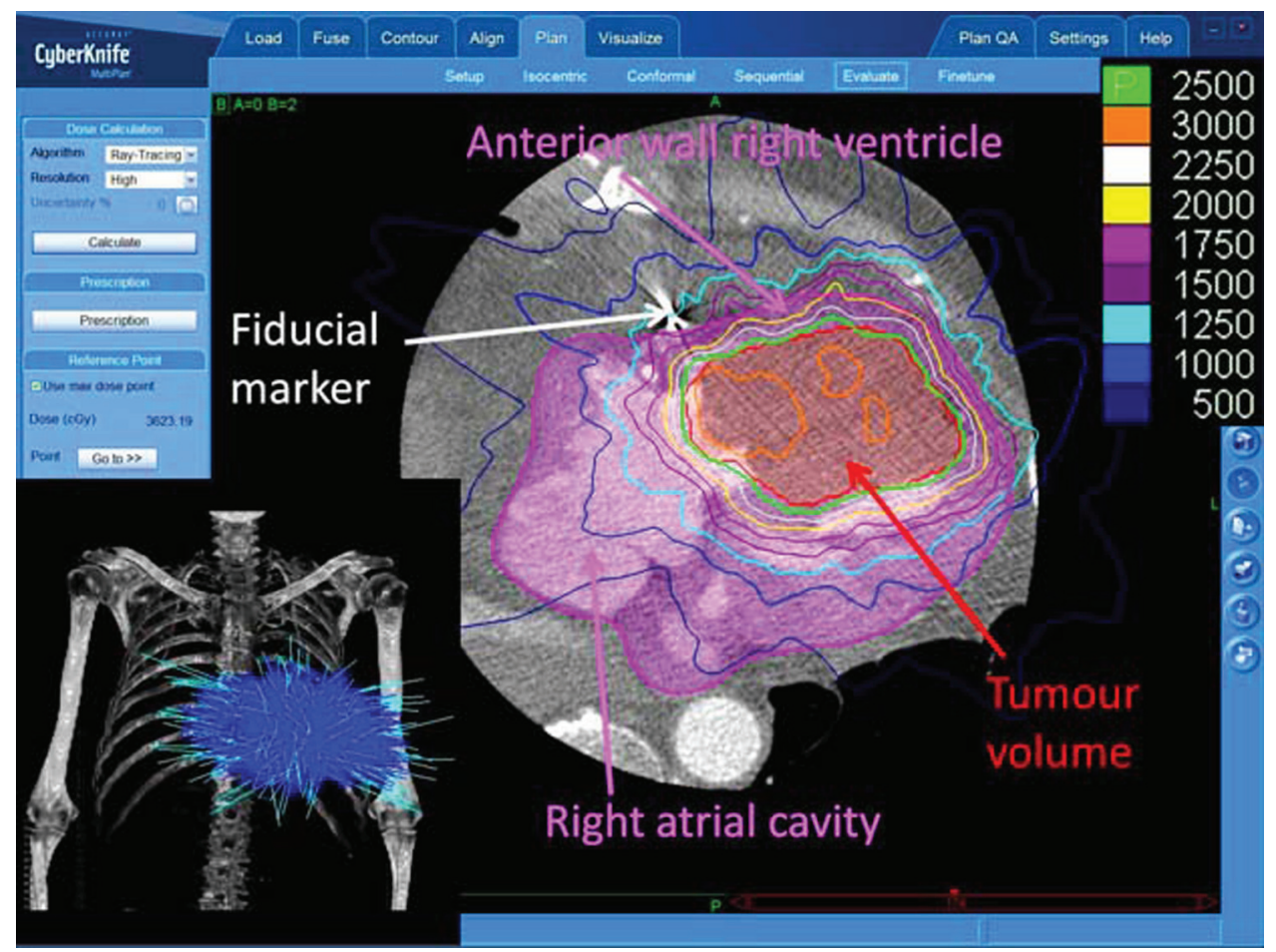

Figure 2 Axial slice from cardiac-gated CT scan used to assist treatment planning. The tumour volume is shown in red overlay, and whole heart volume in pink overlay. The radiation isodose arrangement is superimposed, with the isodose key shown top right (doses are in centigray, where 100 centigray= 1 gray $(G y))$. The radiotherapy beam arrangement is shown on the skeleton view (bottom left). One hundred and ninety eight individual beams of radiation (light blue) converge on the target to give the optimum dose distribution.

cardiac function improved with symptomatic improvement. The patient died 6 months after treatment. The case demonstrates that radiosurgery is a feasible and effective treatment for intracardiac tumours, either with (as in this case) or without previous radiotherapy.
Competing interests Dr Martin and Dr Plowman have received honoraria from Accuray, Sunnyvale, California, USA, for educational presentations related to the use of CyberKnife.

Patient consent Obtained.

This pdf has been created automatically from the final edited text and images.

Copyright 2011 BMJ Publishing Group. All rights reserved. For permission to reuse any of this content visit http://group.bmj.com/group/rights-licensing/permissions.

BMJ Case Report Fellows may re-use this article for personal use and teaching without any further permission.

Please cite this article as follows (you will need to access the article online to obtain the date of publication).

Martin AGR, Coltart DJ, Plowman PN. CyberKnife radiosurgery for an intracardiac metastasis. BMJ Case Reports 2011;10.1136/bcr.07.2010.3197, date of publication

Become a Fellow of BMJ Case Reports today and you can:

- Submit as many cases as you like

- Enjoy fast sympathetic peer review and rapid publication of accepted articles

- Access all the published articles

- Re-use any of the published material for personal use and teaching without further permission

For information on Institutional Fellowships contact consortiasales@bmjgroup.com

Visit casereports.bmj.com for more articles like this and to become a Fellow 